(C) 2020 by the Arizona Board of Regents on behalf of the University of Arizona. This is an Open Access article, distributed under the terms of the Creative Commons Attribution-NonCommercial-Share Alike licence (http://creativecommons.org/licenses/by-nc-sa/4.0/), which permits non-commercial re-use, distribution, and reproduction in any medium, provided the same Creative Commons licence is included and the original work is properly cited. The written permission of Cambridge University Press must be obtained for commercial re-use

\title{
RADIOCARBON DATING OF ORACLE BONES OF LATE SHANG PERIOD IN ANCIENT CHINA - ADDENDUM
}

Kexin Liu $•$ Xiaohong $\mathrm{Wu} \bullet$ Zhiyu Guo $\bullet$ Sixun Yuan $•$ Xingfang Ding • Dongpo Fu • Yan Pan https://doi.org/10.1017/RDC.2020.90, published by Cambridge University Press, 27 October 2020.

KEYWORDS: China, Shang Dynasty, oracle bones, radiocarbon age calibration, radiocarbon dating, addendum.

The authors of this article would like to clarify that Zhiyu Guo and Sixun Yuan are equal corresponding authors of this paper.

\section{REFERENCE}

Liu K, Wu X, Guo Z, Yuan S, Ding X, Fu D, Pan Y.

Shang period in ancient China. Radiocarbon. doi: 2020. Radiocarbon dating of oracle bones of late

10.1017/RDC.2020.90. 